\title{
Diagnostic Evaluation of Pulmonary Embolism: A Computerized Tomography Based Study
}

\author{
Salah Eldein Hassan Aloub, Caroline Edward Ayad \\ College of Medical Radiological Science, Sudan University of Science and Technology, Khartoum, Sudan \\ Email: carolineayad@yahoo.com
}

Received 23 June 2016; accepted 28 July 2016; published 2 August 2016

Copyright @ 2016 by authors and Scientific Research Publishing Inc.

This work is licensed under the Creative Commons Attribution International License (CC BY).

http://creativecommons.org/licenses/by/4.0/

(c) (i) Open Access

\begin{abstract}
Pulmonary embolism (PE) is potentially life threatening condition which requires adequate diagnosis. Since computerized tomography pulmonary angiography (CTPA) described the presence of a clot subjectively, an objective and quantification method to characterize plural parenchymal abnormality, pulmonary vessels and heart is needed (in order to diagnose PE). This study was directed to investigate whether the presence of plural parenchymal findings correlates with the PE and as well, it was designed to answer two basic questions based on CTPA findings done for clinical suspicion of PE: firstly, what are the plural parenchymal abnormalities associated with PE; secondly, correlation of $P E$ with the presence of heart changes and pulmonary vessels measurements. CTPA scans were acquired for 55 patients suspected of having PE and another 50 subjects who were considered as control. The clinical signs and pleuroparenchymal abnormalities, pulmonary artery tree measurements, right ventricle and atrium diameters, Inter ventricular septum width as well as the myocardium thickening were characterized and correlated with PE. The results showed that the PE patients group has more dilated measurements than the normal control subjects. The right ventricle diameter changes were found to be significantly related to the presence of PE at $p \leq 0.001$. Significant changes at $p \leq 0.005$ were also noticed in the pulmonary trunk diameter as well as the right and left main pulmonary arteries with no significant changes detected in the distal portion of both pulmonary arteries diameters. The common complaints from PE patients were chest pain, shortness of breathing, lower limb swelling, tachycardia and syncope. Consolidation, ground glass opacifications, mosaic, right ventricle morphological changes and pleural effusion were present in the majority of patients undergoing CTPA for the clinical suspicion of PE. CTPA is considered as the diagnostic modality of choice in characterization of pulmonary vessels, atrium and ventricle changes as well as pleura parenchymal abnormalities in patients with or without PE.
\end{abstract}

\section{Keywords}

Pulmonary Embolism, Computerized Tomography Pulmonary Angiography, Pleuroparenchymal 


\section{Abnormalities}

\section{Introduction}

Pulmonary embolism (PE) is the most common cardiovascular condition [1]. Death rate after a diagnosis of PE is still $8 \%-15 \%$ [2] [3]. Due to lack of precise symptoms that predict or exclude the diagnosis of PE, it is frequently misdiagnosed [4]. Despite technical progress, imaging the pulmonary arteries has remained costly and harmful, even with noninvasive approaches [5]. PE can be diagnosed accurately with pulmonary angiography, which is recognized as the gold standard, but it is invasive [6].

Imaging modalities have improved over the time from plain film, scintigraphy and angiography to computed tomography (CT) scan and magnetic resonance imaging (MRI), which have been used for diagnosing PE [7]. Contrast-enhanced MRA lacks sufficient spatial resolution for evaluation of peripheral pulmonary arteries [8]. Echocardiography is not recommended as a routine imaging test to diagnose suspected acute PE [9]. Several studies have shown that contrast enhanced CT has sensitivities and specificities of approximately $90 \%$ in the diagnosis of PE [10]-[13]. Spiral computed-tomographic pulmonary angiography (CTPA) has gained a leading role in PE diagnosis because of being less invasive than conventional pulmonary angiography [7]. The main CT limitation is the detection of small peripheral emboli [14]. Early studies comparing spiral CT with selective pulmonary angiography demonstrated the high accuracy of spiral CT for detecting PE [15] but suggested that subsegmental pulmonary emboli may be unnoticed by CT scanning. Recent studies have shown that CT can assess the acute right-sided heart failure and can predict adverse clinical outcome [16] [17]. CT angiography and high resolution CT are commonly used for the diagnosis of PE and underlying lung parenchyma disease [18]-[22]. Asymmetric dilation of the pulmonary arteries, calcified thrombi and bronchial collaterals are considered signs of embolic disease [23] [24]. Deviation of the interventricular septum was reported on CT as a subjective sign of raised right heart pressure. High resolution CT of the chest can show the underlying pulmonary disease [25]. The literature shows variable results for the analytical role of CTPA to characterize the plural parenchymal abnormality, pulmonary vessels and heart in order to diagnose PE. This variability may be explained by the subjective changes on CTPA because formal criteria for establishing these signs are not available. CT can diagnose the presence of a clot subjectively, since an objective and quantification method to characterize plural parenchymal abnormality, pulmonary vessels and heart is needed (in order to diagnose PE). To the best of our knowledge; no study has investigated whether the presence of plural parenchymal findings correlates with the PE in our Sudanese Radiology Departments. This study was directed to investigate whether the presence of plural parenchymal findings correlates with the PE and as well, it was designed to answer two basic questions based on CTPA findings done for clinical suspicion of PE: firstly, what are the plural parenchymal abnormalities associated with PE; secondly, correlation of PE with the presence of heart changes and pulmonary vessels measurements.

\section{Materials and Methods}

\subsection{Area and Duration of the Study}

This study is a descriptive analytical study, it was done at Royal Care International Hospital and Doctor's Clinic Radiology Departments; Data were collected during the period from (October 2013) to (December 2015).

\subsection{Study Population}

A sample of 55 patients with clinically suspected PE was enrolled and 50 subjects were considered as control. Patients mean ages was $54.20 \pm 14.21$ ranged from (28 - 95) years old. The control group mean ages was $50.7 \pm$ 14.5 ranged from (21 - 76) years old. All were examined by using CT. Those were referred to CT examination were with clinical presentation including shortness of breath, chest pain, swallowing in legs. The presumptive diagnosis was based on clinical findings. The normal controls were those who were scanned for CT angiography and their findings were normal without cardiac or vascular or pulmonary problems. Exclusion criteria were non availability of medical records, or have contraindication of intravenous iodinated contrast. Verbal consent was firstly obtained from all potential participants. The aims, benefits of the present study were explained to all par- 
ticipants in details. Medical history of all study subjects posing as (sample) were thoroughly reviewed directly from participants themselves and those with conditions that may in any way, alter the findings of the current study were excluded.

\subsection{Procedure}

\subsubsection{Instrumentation and Scanning Setup}

The CT machines including Toshiba (64 multi-slice detector) and Neo soft (64 multi-slice detector) were used. Contrast-enhanced spiral CT scanning of the pulmonary arteries was performed for the patients in supine position during breath hold, depending on the patient's level of dyspnea. CTA was obtained during spiral data acquisition, the entire area of interest was scanned during the injection of contrast. Images were captured when vessels are fully opacified to demonstrate either arterial or venous phase enhancement through the acquisition of both data sets (arterial and venous). A ROI (region of interest) was positioned over the pulmonary artery at the level of the carina. After commencing the injection a (tracker scan) Hounsfield level at the ROI was monitored and the scan was triggered when the density at the ROI reaches a preset value. Scanning was used to acquire the images of the thorax in a caudal-cranial direction. The caudal-cranial direction was used because most emboli are located in the lower lobes and, if the patient breathes during image acquisition, there is more excursions of the lower lobes compared with the upper lobes. The images were displayed with three different gray scales for interpretation, mediastinal window \{window width-window level (400 - $40 \mathrm{HU})$ \}, Pulmonary embolism-specific window (700 - $1000 \mathrm{HU})$, Lung window (1500 - $600 \mathrm{HU}$ ) settings because pulmonary embolism can be missed when a case with very bright contrast is viewed only on mediastinal window settings. The pulmonary embolismspecific settings were used to help to differentiate between a sharp margined embolus and an ill-defined artifact.

The axial section displaying the maximal distance between the ventricular endocardium, atrium and the interventricular septum, perpendicular to the long axis of the heart, was identified for the right ventricle. The maximum short axis diameters for atrium, ventricle and interventriculer width were measured. Images were obtained with the mediastinal window settings. The main pulmonary artery diameter was measured at its widest portion near its bifurcation at the level of carina, and as well, the right and left pulmonary branches were also been measured. The final diagnosis of PE was made on the basis of the CT findings. The presence, location, of any parenchymal abnormality were identified. The presence of pleural effusions was recorded but it was not been measured or graded.

\subsubsection{System Criteria}

Several scan parameters that were considered carefully are: spiral pitch which is of particular significance because it affects image quality and patient dose. Other parameters are collimation, table speed, duration of the scan, and the reconstruction increment. The used CT Scanning parameter: Collimation (1 - $2 \mathrm{~mm})$, Table speed $(2-4 \mathrm{~mm} / \mathrm{sec})$, Gantry rotation time (ms) $=330-420 \mathrm{~mm} / \mathrm{sec}$, Tube voltage $/(\mathrm{KV})=120 \mathrm{kv}$, Tube current time product $/(\mathrm{mAs})=125 \mathrm{mAs}$, pitch $/(\mathrm{mm})=0.9$, and the reconstruction slice thickness $/(\mathrm{mm})=0.6 \mathrm{CT}$.

Angiography contrast parameters for pulmonary artery: Concentration (mg iodine $/ \mathrm{ml})=350-400$, Injection Rate $(\mathrm{ml} / \mathrm{s})=3 \mathrm{ml} / \mathrm{sec}$, Volume $/(\mathrm{mL})=60-120 \mathrm{ml}$, Delay $(\mathrm{s})=12 \mathrm{sec}$ Saline chaser $(\mathrm{ml}, \mathrm{ml} / \mathrm{s})=30,3.0$.

There are many advantages and disadvantages for the procedure including:

1) Artifacts: -during our scanning respiratory motion artifacts are the most common problem. They are best seen on lung window. Motion artifact renders the diagnosis of PE at the affected anatomic level indeterminate. Therefore the shorter breath-hold technique less than 3 seconds was used to avoid this limitation.

2) Pulmonary artery enhancement: We used attenuation in the artery of at least one more SD; the minimum attenuation of adjacent opacified blood to identify this outlying PE is $210 \mathrm{H}$. To detect abnormalities and to improve pulmonary embolism conspicuity, we adjust the display window widths and levels.

3) Increasing in timing of bolus increases the enhancement of the pulmonary arteries during the injection. This enhancement advantage is used with the delay technique, whereas bolus tracking starts the CT scan earlier on the rise of the enhancement curve and results in worse pulmonary artery enhancement. When the triggering threshold for bolus tracking is increased, CT was started on the rise of the enhancement curve. However, in cases with poor function of the right side of the heart, the enhancement threshold is not reached; this leaves us in doubtful as to when to start image acquisition. The used technique has the advantage of reducing motion artifacts by removing the added density when to start the study based on a threshold value. 
4) Patient habitus was a factor that we considered during the scanning selection criteria; in large patients the image noise and the amount of IV contrast material were increased. For patients weighing more than (100 kg), the radiation dose was increased to decrease the amount of image noise which consider as disadvantage. To decrease image noise and improve scan quality the standard detector width-reconstruction used/(mm) was 0.625 1.25 .

\section{Results}

The following tables and figure presented the results obtained from patients (with PE) and (without PE) scanned using CTPA. All the evaluated variables were measured and tabulated as mean and standard deviation. The comparison between the two groups was obtained using a statistical test for equality of means for the measured variables; the mean difference is significant at the $\mathrm{p} \leq 0.05$ level. Right atrium and right ventricle diameters, pulmonary trunk, right main pulmonary artery, left main pulmonary artery were found to be statistically differs between the two groups (Table 1 and Table 2).

\section{Discussion}

Computed tomography pulmonary angiography (CTPA) has an important role for the detection of pulmonary embolism (PE) in large and segmental vessels [26]-[30]. The pulmonary vessels were evaluated and measured including main pulmonary trunk, right and left pulmonary vessels as well as the proximal and distal segment and were compared with the normal controls, this was presented in Table 1 and Table 2 . The results showed the PE patients group has dilated measurement when compared with the normal control subjects. The changes were found to be: for the right atrium; it was found to be larger by $3.1 \mathrm{~mm}$, right ventricle by $3.8 \mathrm{~mm}$, interventricular septum width by $0.4 \mathrm{~mm}$, myocardium thickening $0.21 \mathrm{~mm}$. In the current study the CT quantification method

Table 1. Descriptive statistics (mean and standard deviation) of the studied variables in patients with and without pulmonary embolism.

\begin{tabular}{|c|c|c|c|c|c|c|}
\hline Variables & Sample & $\mathbf{N}$ & Mean (mm) & Std. Deviation & Minimum (mm) & Maximum (mm) \\
\hline \multirow{2}{*}{ Right Atrium Diameter } & With PE & 55 & 49.51 & 8.54 & 33.20 & 87.30 \\
\hline & Without PE & 50 & 46.43 & 6.44 & 36.70 & 77.00 \\
\hline \multirow{2}{*}{ Right Ventricle Diameter } & With PE & 55 & 46.03 & 6.23 & 32.90 & 68.30 \\
\hline & Without PE & 50 & 42.25 & 3.85 & 35.60 & 53.70 \\
\hline \multirow{2}{*}{ Interventricular Septum Width } & With PE & 55 & 11.38 & 1.82 & 8.30 & 20.80 \\
\hline & Without PE & 50 & 11.00 & 1.13 & 8.30 & 13.00 \\
\hline \multirow{2}{*}{ Myocardium Thickening } & With PE & 55 & 7.16 & 0.97 & 5.50 & 10.50 \\
\hline & Without PE & 50 & 6.95 & 0.77 & 5.30 & 9.60 \\
\hline \multirow{2}{*}{ Pulmonary Trunk Diameter } & With PE & 55 & 28.00 & 3.70 & 19.50 & 37.10 \\
\hline & Without PE & 50 & 25.17 & 3.33 & 19.00 & 34.30 \\
\hline \multirow{2}{*}{ Right Main Pulmonary Artery Diameter } & With PE & 55 & 20.70 & 3.33 & 15.40 & 29.70 \\
\hline & Without PE & 50 & 18.89 & 2.81 & 12.90 & 25.10 \\
\hline \multirow{2}{*}{ Left Main Pulmonary Artery Diameter } & With PE & 55 & 21.05 & 3.37 & 15.20 & 30.00 \\
\hline & Without PE & 50 & 19.56 & 3.02 & 14.10 & 26.70 \\
\hline \multirow{2}{*}{ Right Distal Pulmonary Artery Diameter } & With PE & 55 & 3.21 & 0.40 & 2.50 & 4.50 \\
\hline & Without PE & 50 & 3.22 & 0.32 & 2.50 & 4.10 \\
\hline \multirow{2}{*}{ Left Distal Pulmonary Artery Diameter } & With PE & 55 & 3.23 & 0.38 & 2.60 & 4.80 \\
\hline & Without PE & 50 & 3.15 & 0.29 & 2.40 & 3.80 \\
\hline
\end{tabular}


Table 2. Independent samples test for equality of means shows the difference between patients with and without pulmonary embolism.

\begin{tabular}{ccc}
\hline Independent Samples Test & & \\
\hline Patients with and without Pulmonary Embolism & t-test for Equality of Means \\
\hline Right Atrium Diameter & $\mathrm{t}$ & Sig. (2-tailed) \\
Right Ventricle Diameter & 2.071 & $0.041^{*}$ \\
Inter Ventricular Septum Width & 3.692 & $0.000^{*}$ \\
Myocardium Thickening & 1.281 & 0.203 \\
Pulmonary Trunk Diameter & 1.233 & 0.220 \\
Right Main Pulmonary Artery Diameter & 4.100 & $0.000^{*}$ \\
Left Main Pulmonary Artery Diameter & 3.006 & $0.003^{*}$ \\
Right Distal Pulmonary Artery Diameter & 2.370 & $0.020^{*}$ \\
Left Distal Pulmonary Artery Diameter & -0.102 & 0.919 \\
\hline
\end{tabular}

"The mean difference is significant at the 0.05 level.

of measurement reflects changes happened due to PE; similarly a quantitative method has been reported to have good correlation to pulmonary angiography indices [31]. For this purpose, the arterial changes were also been evaluated and was quantified by measuring the diameter in ( $\mathrm{mm}$ ) in axial CT images based on the location of the embolus. A significant changes were also been noticed in the pulmonary trunk diameter as well as the right and left main pulmonary artery without any significant changes detected in the distal portion of both of the pulmonary arteries (Table 2).

Studies have mentioned that some cases may not be diagnosed clinically because symptoms such as chest pain, shortness of breath, and tachycardia are nonspecific and may mimic other pulmonary or cardiac conditions [32]. In our study the most common patient complains in PE patient's were found to be chest pain that constituting 38/55 (69.1\%), followed by shortness of breathing which was found in 33/55 (60\%) of the sample. The least percent were for tachycardia and syncope as presented in Table 3. PE was found unilaterally in 34 (61.8\%) cases and bilaterally in 21 (38.2\%). Our study showed an adverse result when compared to the study done previously [32] is that PE is more often bilateral than unilateral. It has been estimated that $80 \%$ of PE cases are associated with deep vein thrombosis (DVT). It is therefore noticed that PE is considered a complication or a consequence of DVT [33]. A concern with this approach is that some cases of PE are due to embolization from other sites, such as pelvic or upper-extremity veins or the right heart, therefore the patients lower limbs were also been evaluated. Leg swelling was found only in 2/55 (3.6\%) of the sample with no significant relationship was detected in our sample. An abnormal right ventricle morphology was also found in 11/55 (20\%) of the patients with PE and the changes were found to be significantly affected with the presence of PE at $p \leq 0.001$, this was noticed in Table 3.

In recent studies using computed tomography (CT) it is not only has a great role in demonstrating intra luminal clot, but CTPA also allows concomitant evaluation of the lung parenchyma and pleural space [32]. Furthermore, very few studies have addressed the prevalence and spectrum of parencyhmal and pleural findings in the setting of PE [34]-[37]. In the present study, we sought to resolve the influence of the presence of pulmonary arterial obstruction from acute PE on the presence and extent of pleura parenchymal abnormalities. To our knowledge, this is the first Sudanese study performed to correlate PE to pleura parenchymal findings. When we did so, we found that the parenchymal abnormalities detected were: 1) pleural effusion which was found in $21 / 55(38.2 \%)$ and was significantly correlated at $\mathrm{p} \leq 0.000$. When it was characterized it was found to be wedge-shaped opacity with a roughly triangular area of increased attenuation, with a broad base against pleural surface and the apex toward the hilum was noticed; 2) consolidation constituting 25/55 (45.5\%) and was correlated also significantly at $\mathrm{p} \leq 0.041$, it was characterized as a non-wedge-shaped area of increased attenuation obscuring broncho vascular markings, and was more prominent in patients with PE than in patients without PE 
Table 3. The frequency of the complains findings in patients with and without pulmonary embolism.

\begin{tabular}{|c|c|c|c|}
\hline Complain & Presence/Absence & Patients with (PE) N = 55 & Patients without $(\mathrm{PE}) \mathrm{N}=50$ \\
\hline \multirow{5}{*}{ Chest pain } & \multirow{2}{*}{ Present } & 38 & 23 \\
\hline & & $69.1 \%$ & $46.9 \%$ \\
\hline & \multirow{3}{*}{ Absent } & & \\
\hline & & 17 & 26 \\
\hline & & $30.9 \%$ & $53.1 \%$ \\
\hline \multirow{4}{*}{ Shortness of breathing } & \multirow{2}{*}{ Present } & 33 & 39 \\
\hline & & $60.0 \%$ & $78.0 \%$ \\
\hline & \multirow{2}{*}{ Absent } & 22 & 11 \\
\hline & & $40.0 \%$ & $22.0 \%$ \\
\hline \multirow{4}{*}{ Leg swelling } & \multirow{2}{*}{ Present } & 2 & 3 \\
\hline & & $3.6 \%$ & $6.0 \%$ \\
\hline & \multirow{2}{*}{ Absent } & 53 & 47 \\
\hline & & $96.4 \%$ & $94.0 \%$ \\
\hline \multirow{5}{*}{ Tachycardia } & \multirow{3}{*}{ Present } & 1 & 0 \\
\hline & & & \\
\hline & & $1.8 \%$ & $0.0 \%$ \\
\hline & \multirow{2}{*}{ Absent } & 54 & 50 \\
\hline & & $98.2 \%$ & $100.0 \%$ \\
\hline \multirow{4}{*}{ Syncope } & \multirow{2}{*}{ Present } & 1 & 0 \\
\hline & & $1.8 \%$ & $0.0 \%$ \\
\hline & \multirow{2}{*}{ Absent } & 54 & 50 \\
\hline & & $98.2 \%$ & $100.0 \%$ \\
\hline
\end{tabular}

in our series. These findings agreed with those of Reissig et al. [36], who reported significantly higher frequency of non-wedge-shaped consolidations in patients with PE than in patients without PE. However, the frequency of consolidation was lower in other studies investigating the parenchyma findings in the setting of PE [34] [35] [37]. The higher prevalence of consolidation in patients with PE can be explained by the proposal that it may represent a non-wedge shaped infarct, edema or hemorrhage; however, consolidation is a nonspecific pattern that can result from many different causes. Our findings confirm the previous studies reporting significant association for ground glass in patients with PE [34]-[36]. In our series 13 (26.0\%) patients without PE had a non wedge-shaped opacity that could be attributable to another cause.

The another findings in our study is; 3) ground-glass attenuation which was one of the parenchymal finding, seen in patients with PE but the least percentage was found in only 3 cases (5.5\%), from four previous studies [34]-[37] designed to identify subsidiary CT findings in the setting of acute PE, only Shah et al. [35] searched for ground-glass attenuation, and reported that it was seen in $14 \%$ of patients with PE, and in $25 \%$ of patients without PE and was found to enclose the attenuation of a hazy increased parenchymal attenuation not obscuring broncho vascular markings. These findings were consistent to the description done by Nevzat Karabulut et al. (2008) [32]. The presence of ground glass opacity in patients with acute PE can be explained by the alteration of lung attenuation values by diminished pulmonary perfusion, broncho constriction, or edema; this was also similarly mentioned by Matsuoka et al. [38].

Mosaic appearance was seen in 5 (9.1\%) of patients with PE and only 1 (2.0\%) in non PE subjects. Literature has mentioned that PE can cause a no uniform arterial perfusion pattern that can manifest as a mosaic pattern of lung attenuation on CT [39] this was also found in our study. The presence of one non embolic case complaining of the mosaic pattern of lung attenuation may be due to other causes [40]. 
Right ventricle (RV) was found to be abnormal in 11 (20.0\%) patients with PE and only one case (2.0\%) none affected with PE was consider having abnormal RV (Table 4). This circumstances should be considered critical because it was mentioned that PE increases the pressure of the pulmonary arterial system and right ventricle (RV) resulting in RV dysfunction, which may progress to right heart failure and circulatory collapse [41] [42]. That led to higher mortality rate than those without [42] [43]. Thus, the presence of RV dysfunction is a marker for adverse clinical outcome in patients with PE as mentioned by similar previous studies [9] [42] [43].

Previous studies have mentioned that Pulmonary CTA allows visualization of emboli and provides information regarding the status of the right heart [44] [45]. In several studies, the ratio of the RV to left ventricle (LV) diameters on pulmonary CTA has been proposed as a sign for RV abnormality [17] [46] [47]. Other signs have been described, including bowing of the interventricular septum [48] [49]. However, a variety of different methods for the quantitative assessment of RV on pulmonary CTA have been proposed [17] [46] [47] [50] and the literature shows variable results for the prognostic power of pulmonary CTA signs of RV problems to predict adverse outcomes. This variability may in part be explained by the somewhat subjective nature of diagnosing RV changes on pulmonary CTA because formal criteria for establishing these signs are not available. It is noteworthy that several prior publications on this topic [48] [51]-[53] do not report interobserver reproducibility of the findings. The current study evaluated both patients with PE and without PE by measuring the heart and right atrium diameter, right ventricle diameter and inter ventricular septum width with quantification method. Changes were proposed to be sign of PE and we believe that these findings should be acknowledged in the diagnosis of PE and associated clinical and radiological findings.

Comparing between the patients age groups with and without pulmonary embolism; the study revealed that the most affected age group with PE was identified between 51 - 60 years, constituting 18/55 (32.7\%) with significantly correlated at $\mathrm{p} \leq 0.036$ this was presented in (Figure 1 ).

Table 4. The frequency of parenchymal findings in patients with and without pulmonary embolism.

\begin{tabular}{|c|c|c|c|}
\hline Parenchyma Findings & Condition & Patients with (PE) N = 55 & Patients without $(\mathrm{PE}) \mathrm{N}=50$ \\
\hline \multirow{4}{*}{ Associated Pleural Effusion } & \multirow{2}{*}{ Present } & 21 & 34 \\
\hline & & $38.2 \%$ & $68.0 \%$ \\
\hline & \multirow{2}{*}{ Absent } & 34 & 16 \\
\hline & & $61.8 \%$ & $32.0 \%$ \\
\hline \multirow{4}{*}{ Consolidation } & \multirow{2}{*}{ Present } & 25 & 13 \\
\hline & & $45.5 \%$ & $26.0 \%$ \\
\hline & \multirow{2}{*}{ Absent } & 30 & 37 \\
\hline & & $54.5 \%$ & $74.0 \%$ \\
\hline \multirow{4}{*}{ Ground Glass Opacity } & \multirow{2}{*}{ Present } & 3 & 3 \\
\hline & & $5.5 \%$ & $6.0 \%$ \\
\hline & \multirow{2}{*}{ Absent } & 52 & 47 \\
\hline & & $94.5 \%$ & $94.0 \%$ \\
\hline \multirow{4}{*}{ Mosaic Appearance } & \multirow{2}{*}{ Present } & 5 & 1 \\
\hline & & $9.1 \%$ & $2.0 \%$ \\
\hline & \multirow{2}{*}{ Absent } & 50 & 49 \\
\hline & & $90.9 \%$ & $98.0 \%$ \\
\hline \multirow{4}{*}{ Right Ventricle Morphology } & \multirow{2}{*}{ Normal } & 44 & 49 \\
\hline & & $80.0 \%$ & $98.0 \%$ \\
\hline & \multirow{2}{*}{ Abnormal } & 11 & 1 \\
\hline & & $20.0 \%$ & $2.0 \%$ \\
\hline
\end{tabular}

\footnotetext{
"PE was found unilaterally in 34 (61.8\%) cases and bilaterally in 21 (38.2\%).
} 


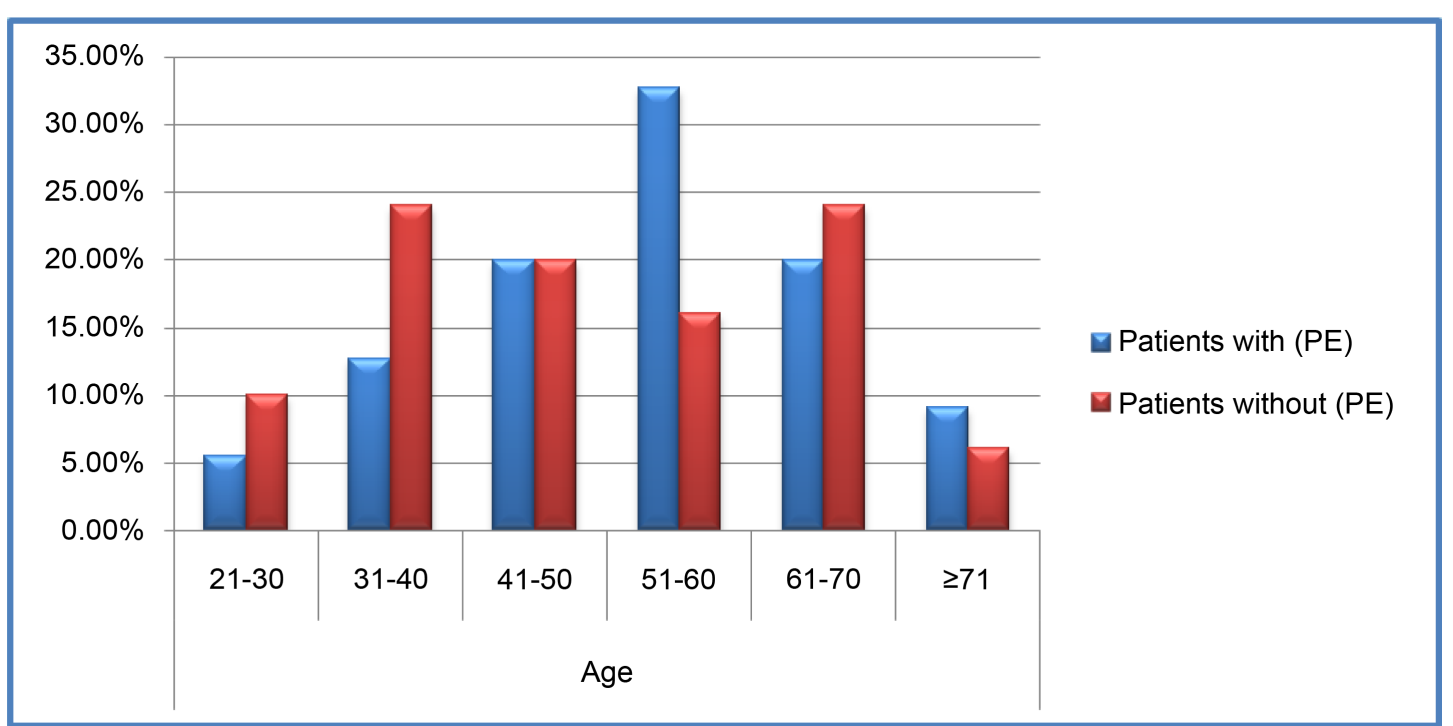

Figure 1. Distribution of patients with PE $(n=55)$ and without PE $(n=50)$ according to age classes presented in percentage.

\section{Conclusions}

CTPA has changed the diagnostic step up for suspected pulmonary embolism. CT not only provides concrete evidence of an embolus, but also allows the concurrent evaluation of other intrathoracic structures. Nevertheless, routine interpretation of CTPA findings is typically focused on the presence or absence of emboli along with a rough visual estimation of clot, and a description of pleura parenchymal abnormalities. Only recently studies have been focused on the quantification of clot on the basis of CTPA findings [31] [52]-[56]. Other quantification methods were used to diagnose PE including blood gas values and lung attenuation [52]-[56]. Collomb et al. [48] found that the pulmonary arterial obstruction can be used as an indicator for presence of PE. Other investigators, Van Der Meer et al. [52] and Wu et al. [54], reported that the CT is a significant predictor of death.

Regarding the current study results, the answers of the two raised questions based on findings of CTPA performed for clinical suspicion of PE have been answered: consolidation, ground glass opacifications, and mosaic, right ventricle morphological changes and pleural effusion were found to be present in the majority of patients undergoing CTPA for the clinical suspicion of PE. The presence of heart changes and pulmonary vessels measurements findings were found to have correlation with the presence of PE. The clinical implication of this finding is likely to be different in patients with PE. CTPA is considered as the diagnostic modality of choice in the characterization of pulmonary vessels, atrium and ventricle changes as well as pleura parenchymal abnormalities in patients with or without PE.

\section{References}

[1] Giuntini, C., Di Ricco, G., Marini, C., Melillo, E. and Palla, A. (1995) Pulmonary Embolism: Epidemiology. Chest, 107, 3S-9S. http://dx.doi.org/10.1378/chest.107.1_Supplement.3S

[2] Carson, J.L., Kelley, M.A., Duff, A., et al. (1992) The Clinical Course of Pulmonary Embolism. The New England Journal of Medicine, 326, 1240-1245. http://dx.doi.org/10.1056/NEJM199205073261902

[3] Stein, P.D., Kayali, F. and Olson, R.E. (2004) Trends in the Use of Diagnostic Imaging in Patients Hospitalized with Acute Pulmonary Embolism. American Journal of Cardiology, 93, 1316-1317. http://dx.doi.org/10.1016/j.amjcard.2004.02.022

[4] Doğan, H., de Roos, A., Geleijins, J., Huisman, M.V. and Kroft, L.J. (2015) The Role of Computed Tomography in the Diagnosis of Acute and Chronic Pulmonary Embolism. Diagnostic and Interventional Radiology, 21, 307-316. http://dx.doi.org/10.5152/dir.2015.14403

[5] Schoepf, U.J., Goldhaber, S.Z. and Costello, P. (2004) Spiral Computed Tomography for Acute Pulmonary Embolism. Circulation, 109, 2160-2167. http://dx.doi.org/10.1161/01.CIR.0000128813.04325.08

[6] Stein, P.D., Athanasoulis, C. and Alavi, A. (1992) Complications and Validity of Pulmonary Angiography in Acute 
Pulmonary Embolism. Circulation, 85, 462-468. http://dx.doi.org/10.1161/01.CIR.85.2.462

[7] Akhtar, W., Hussain, M., Haider, Z., Gul-e-Khanda and Chisthy, I.A. (2010) Computed Tomography (CT) Scan for Pulmonary Embolism. Journal of Liaquat University of Medical and Health Sciences, 9, 101-105.

[8] Oudkerk, M., van Beek, E.J., Wielopolski, P., et al. (2002) Comparison of Contrast Enhanced Magnetic Resonance Angiography and Conventional Pulmonary Angiography for the Diagnosis of Pulmonary Embolism: A Prospective Study. Lancet, 359, 1643-1647. http://dx.doi.org/10.1016/S0140-6736(02)08596-3

[9] Goldhaber, S.Z. (2002) Echocardiography in the Management of Pulmonary Embolism. Annals of Internal Medicine, 136, 691-700. http://dx.doi.org/10.7326/0003-4819-136-9-200205070-00012

[10] Usman, M.U., Bari, V., Yaqoob, J. and Murad, M. (2003) Diagnosis of Pulmonary Embolism with Helical CT Scan. JPMA, 53, 354-356.

[11] Pineda, L.A., Hathwar, V.S. and Grant, B.J. (2001) Clinical Suspicion of Fatal Pulmonary Embolism. Chest, 120, 791795. http://dx.doi.org/10.1378/chest.120.3.791

[12] Wittram, C. (2007) How I Do It: CT Pulmonary Angiography. American Journal of Roentgenology, 188, $1255-1261$. http://dx.doi.org/10.2214/AJR.06.1104

[13] Subramaniam, R.M., Mandrekar, J., Chang, C., Blair, D., Gilbert, K., et al. (2008) Pulmonary Embolism Outcome: A Prospective Evaluation of CT Pulmonary Angiographic Clot Burden Score and ECG Score. American Journal of Roentgenology, 190, 1599-1604. http://dx.doi.org/10.2214/AJR.07.2858

[14] Perrier, A., Howarth, N., Didier, D., et al. (2001) Performance of Helical Computed Tomography in Unselected Outpatients with Suspected Pulmonary Embolism. Annals of Internal Medicine, 135, 88-97. http://dx.doi.org/10.7326/0003-4819-135-2-200107170-00008

[15] Remy-Jardin, M., Remy, J., Deschildre, F., et al. (1996) Diagnosis of Pulmonary Embolism with Spiral CT: Comparison with Pulmonary Angiography and Scintigraphy. Radiology, 200, 699-706.

http://dx.doi.org/10.1148/radiology.200.3.8756918

[16] Quiroz, R., Kucher, N., Schoepf, U.J., et al. (2004) Right Ventricular Enlargement on Chest Computed Tomography: Prognostic Role in Acute Pulmonary Embolism. Circulation, 109, 2401-2404. http://dx.doi.org/10.1161/01.CIR.0000129302.90476.BC

[17] Reid, J.H. and Murchison, J.T. (1998) Acute Right Ventricular Dilatation: A New Helical CT Sign of Massive Pulmonary Embolism. Clinical Radiology, 53, 694-698. http://dx.doi.org/10.1016/S0009-9260(98)80297-3

[18] Moraes, D. and Localzo, J. (1997) Pulmonary Hypertension: Newer Concepts in Diagnosis and Management. Clinical Cardiology, 20, 676-682. http://dx.doi.org/10.1002/clc.4960200804

[19] Runo, J. and Loyd, J. (2003) Primary Pulmonary Hypertension. The Lancet, 361, 1533-1544. http://dx.doi.org/10.1016/S0140-6736(03)13167-4

[20] Budev, M.M., Arroliga, A.C. and Jenning, C.A. (2003) Diagnosis and Evaluation of Pulmonary Hypertension. Cleveland Clinic Journal of Medicine, 70, S9-S17.

[21] Bugnone, A., Viamonte, M. and Garcia, H. (2002) Imaging Findings in HIV-Related Pulmonary Hypertension: Report of Five Cases and Review of the Literature. Radiology, 223, 820-827. http://dx.doi.org/10.1148/radiol.2233010911

[22] Hey, J.C. and Scharf, S.M. (2003) Pulmonary Arterial Hypertension-The Primary Pulmonary Hypertension Syndromes. The Israel Medical Association Journal, 5, 298-303.

[23] Tans, R.T., Kuzo, R. and Goodman, L. (1998) Utility of CT Scan for Predicting Pulmonary Hypertension in Patient with Parenchymal Lung Disease. Chest, 113, 1250-1256. http://dx.doi.org/10.1378/chest.113.5.1250

[24] Bergeen, J.B. (1997) Chronic Thromboembolic Pulmonary Hypertension: The Disease, the Diagnosis and the Treatment. Seminars in Ultrasound, CT, and MRI, 18, 383-391. http://dx.doi.org/10.1016/S0887-2171(97)90016-0

[25] Sherrick, A., Swensen, S. and Hartman, T. (1997) Mosaic Pattern of Lung Attenuation on CT Scans: Frequency among Patients with Pulmonary Artery Hypertension of Different Causes. American Journal of Roentgenology, 169, 79-82. http://dx.doi.org/10.2214/ajr.169.1.9207504

[26] Weiss, C.R., Scatarige, J.C., Diette, G.B., Haponik, E.F., Merriman, B. and Fishman, E.K. (2006) CT Pulmonary Angiography Is the First-Line Imaging Test for Acute Pulmonary Embolism: A Survey of US Clinicians. Academic Radiology, 13, 434-446. http://dx.doi.org/10.1016/j.acra.2006.01.002

[27] Ghaye, B., Ghuysen, A., Bruyere, P.J., D’Orio, V. and Dondelinger, R.F. (2006) Can CT Pulmonary Angiography Allow Assessment of Severity and Prognosis in Patients Presenting with Pulmonary Embolism? What the Radiologist Needs to Know. RadioGraphics, 26, 23-39. http://dx.doi.org/10.1148/rg.261055062

[28] Stein, P.D., Woodard, P.K., Weg, J.G., et al. (2007) Diagnostic Pathways in Acute Pulmonary Embolism: Recommendations of the PIOPED II Investigators. Radiology, 242, 15-21. http://dx.doi.org/10.1148/radiol.2421060971 
[29] Ghaye, B., Remy, J. and Remy-Jardin, M. (2002) Non Traumatic Thoracic Emergencies: CT Diagnosis of Acute Pulmonary Embolism-The First 10 Years. European Radiology, 12, 1886-1905. http://dx.doi.org/10.1007/s00330-002-1506-z

[30] Schoepf, U.J. and Costello, P. (2004) CT Angiography for Diagnosis of Pulmonary Embolism: State of the Art. Radiology, 230, 329-337. http://dx.doi.org/10.1148/radiol.2302021489

[31] Qanadli, S.D., El Hajjam, M., Vieillard-Baron, A., et al. (2001) New CT Index to Quantify Arterial Obstruction in Pulmonary Embolism: Comparison with Angiographic Index and Echocardiography. American Journal of Roentgenology, 176, 1415-1420. http://dx.doi.org/10.2214/ajr.176.6.1761415

[32] Karabulut, N. and Kiroğlu, Y. (2008) Relationship of Parenchymal and Pleural Abnormalities with Acute Pulmonary Embolism: CT Findings in Patients with and without Embolism. Diagnostic and Interventional Radiology, 14, 189196.

[33] Stein, P.D., Hull, R.D., Saltzman, H.A. and Pineo, G. (1993) Strategy for Diagnosis of Patients with Suspected Acute Pulmonary Embolism. Chest, 103, 1553-1559. http://dx.doi.org/10.1378/chest.103.5.1553

[34] Coche, E.E., Muller, N.L., Kim, K.I., Wiggs, B.R. and Mayo, J.R. (1998) Acute Pulmonary Embolism: Ancillary Findings at Spiral CT. Radiology, 207, 753-758. http://dx.doi.org/10.1148/radiology.207.3.9609900

[35] Shah, A.A., Davis, S.D., Gamsu, G. and Intriere, L. (1999) Parenchymal and Pleural Findings in Patients with and Patients without Acute Pulmonary Embolism Detected at Spiral CT. Radiology, 211, 147-153. http://dx.doi.org/10.1148/radiology.211.1.r99ap03147

[36] Reissig, A., Heyne, J.P. and Kroegel, C. (2004) Ancillary Lung Parenchymal Findings at Spiral CT Scanning in Pulmonary Embolism. Relationship to Chest Sonography. European Journal of Radiology, 49, 250-257. http://dx.doi.org/10.1016/S0720-048X(03)00141-4

[37] Johnson, P.T., Wechsler, R.J., Salazar, A.M., Fisher, A.M., Nazarian, L.N. and Steiner, R.M. (1999) Spiral CT of Acute Pulmonary Thrombo Embolism: Evaluation of Pleuroparenchymal Abnormalities. Journal of Computer Assisted Tomography, 23, 369-373. http://dx.doi.org/10.1097/00004728-199905000-00009

[38] Matsuoka, S., Kurihara, Y., Yagihashi, K., Niimi, H. and Nakajima, Y. (2006) Quantification of Thin-Section CT Lung Attenuation in Acute Pulmonary Embolism: Correlations with Arterial Blood Gas Levels and CT Angiography. American Journal of Roentgenology, 186, 1272-1279. http://dx.doi.org/10.2214/AJR.05.0047

[39] Gottschalk, A., Stein, P.D., Goodman, L.R. and Sostman, H.D. (2002) Overview of Prospective Investigation of Pulmonary Embolism Diagnosis II. Seminars in Nuclear Medicine, 32, 173-182. http://dx.doi.org/10.1053/snuc.2002.124177

[40] Wittram, C., Kalra, M.K., Maher, M.M., Greenfield, A., McLoud, T.C. and Shepard, J.-A.O. (2006) Acute and Chronic Pulmonary Emboli: Angiography-CT Correlation. American Journal of Roentgenology, 186, S421-S429.

[41] Kasper, W., Konstantinides, S., Geibel, A., et al. (1997) Management Strategies and Determinants of Outcome in Acute Major Pulmonary Embolism: Results of a Multicenter Registry. Journal of the American College of Cardiology, 30, 1165-1171. http://dx.doi.org/10.1016/S0735-1097(97)00319-7

[42] Ribeiro, A., Lindmarker, P., Juhlin-Dannfelt, A., Johnsson, H. and Jorfeldt, L. (1997) Echocardiography Doppler in Pulmonary Embolism: Right Ventricular Dysfunction as a Predictor of Mortality Rate. American Heart Journal, 134, 479-487. http://dx.doi.org/10.1016/S0002-8703(97)70085-1

[43] Grifoni, S., Olivotto, I., Cecchini, P., et al. (2000) Short-Term Clinical Outcome of Patients with Acute Pulmonary Embolism, Normal Blood Pressure, and Echo Cardiographic Right Ventricular Dysfunction. Circulation, 101, 28172822. http://dx.doi.org/10.1161/01.CIR.101.24.2817

[44] Ocak, I. and Fuhrman, C. (2008) CT Angiography Findings of the Left Atrium and Right Ventricle in Patients with Massive Pulmonary Embolism. American Journal of Roentgenology, 191, 1072-1076. http://dx.doi.org/10.2214/AJR.07.3715

[45] Oliver, T.B., Reid, J.H. and Murchison, J.T. (1998) Interventricular Septal Shift Due to Massive Pulmonary Embolism Shown by CT Pulmonary Angiography: An Old Sign Revisited. Thorax, 53, 1092-1094. http://dx.doi.org/10.1136/thx.53.12.1092

[46] Contractor, S., Maldjian, P.D., Sharma, V.K. and Gor, D.M. (2002) Role of Helical CT in Detecting Right Ventricular Dysfunction Secondary to Acute Pulmonary Embolism. Journal of Computer Assisted Tomography, 26, 587-591. http://dx.doi.org/10.1097/00004728-200207000-00020

[47] Araoz, P.A., Gotway, M.B., Trowbridge, R.L., et al. (2003) Helical CT Pulmonary Angiography Predictors of Inhospital Morbidity and Mortality in Patients with Acute Pulmonary Embolism. Journal of Thoracic Imaging, 18, 207-216. http://dx.doi.org/10.1097/00005382-200310000-00001

[48] Collomb, D., Paramelle, P.J., Calaque, O., et al. (2003) Severity Assessment of Acute Pulmonary Embolism: Evalua- 
tion Using Helical CT. European Radiology, 13, 1508-1514. http://dx.doi.org/10.1007/s00330-002-1804-5

[49] Aviram, G., Rogowski, O., Gotler, Y., et al. (2008) Real-Time Risk Stratification of Patients with Acute Pulmonary Embolism by Grading the Reflux of Contrast Medium into the Inferior Vena Cava on Computerized Tomographic Pulmonary Angiography. Journal of Thrombosis and Haemostasis, 6, 1488-1493.

[50] Mansencal, N., Joseph, T., Vieillard-Baron, A., et al. (2005) Diagnosis of Right Ventricular Dysfunction in Acute Pulmonary Embolism Using Helical Computed Tomography. The American Journal of Cardiology, 95, 1260-1263. http://dx.doi.org/10.1016/j.amjcard.2005.01.064

[51] He, H., Stein, M.W., Zalta, B. and Haramati, L.B. (2006) Computed Tomography Evaluation of Right Heart Dysfunction in Patients with Acute Pulmonary Embolism. Journal of Computer Assisted Tomography, 30, 262-266. http://dx.doi.org/10.1097/00004728-200603000-00018

[52] Van der Meer, R.W., Pattynama, P.M., van Strijen, M.J., et al. (2005) Right Ventricular Dysfunction and Pulmonary Obstruction Index at Helical CT: Prediction of Clinical Outcome during 3-Month Follow-Up in Patients with Acute Pulmonary Embolism. Radiology, 235, 798-803. http://dx.doi.org/10.1148/radiol.2353040593

[53] Doğan, H., Kroft, L.J., Huisman, M.V., van der Gees, R.J. and de Roos, A. (2007) Right Ventricular Function in Patients with Acute Pulmonary Embolism: Analysis with Electrocardiography-Synchronized Multi-Detector Row CT. Radiology, 242, 78-84. http://dx.doi.org/10.1148/radiol.2421052089

[54] Wu, A.S., Pezzullo, J.A., Cronan, J.J., Hou, D.D. and Mayo-Smith, W.W. (2004) CT Pulmonary Angiography: Quantification of Pulmonary Embolus as a Predictor of Patient Outcome-Initial Experience. Radiology, 230, 831-835. http://dx.doi.org/10.1148/radiol.2303030083

[55] Ghaye, B., Ghuysen, A., Willems, V., et al. (2006) Severe Pulmonary Embolism: Pulmonary Artery Clot Load Scores and Cardiovascular Parameters as Predictors of Mortality. Radiology, 239, 884-891. http://dx.doi.org/10.1148/radiol.2392050075

[56] Pech, M., Wieners, G., Dul, P., et al. (2007) Computed Tomography Pulmonary Embolism Index for the Assessment of Survival in Patients with Pulmonary Embolism. European Radiology, 17, 1954-1959. http://dx.doi.org/10.1007/s00330-007-0577-2

\section{Submit or recommend next manuscript to SCIRP and we will provide best service for you:}

Accepting pre-submission inquiries through Email, Facebook, LinkedIn, Twitter, etc. A wide selection of journals (inclusive of 9 subjects, more than 200 journals)

Providing 24-hour high-quality service

User-friendly online submission system

Fair and swift peer-review system

Efficient typesetting and proofreading procedure

Display of the result of downloads and visits, as well as the number of cited articles

Maximum dissemination of your research work

Submit your manuscript at: http://papersubmission.scirp.org/ 